\title{
Influence of hull entrance angle "Perintis 750 DWT", toward ship resistance: the case study for design development "Perintis 750 DWT."
}

\author{
Eko Sasmito Hadi ${ }^{1,1}$, Parlindungan Manik ${ }^{1}$, and Muhammad Iqbal $^{1}$ \\ ${ }^{1}$ Department of Naval Architecture, Diponegoro University, Semarang 50275, Indonesia
}

\begin{abstract}
Geographically Indonesia which most of its territory consists of the sea, causing the necessity of strengthening maritime facilities and infrastructure to conduct activities of distribution of goods and sea transportation facilities, especially ships as a vehicle of sea transportation to maintain inter-island connectivity. Indonesian government builds national connectivity (sea tolls) by the development of pioneer ship design "Kapal Perintis.". In this study, the vessel Perintis 750 DWT is still lacking in the EEDI (Energy Efficiency Design Index) aspect as required by IMO, so it is necessary to modify the hull part of the vessel to reduce the resistance. The modified hull is carried out by varying the angle of entrance bow of the ship $\pm 12^{\circ}$ in step of $3^{\circ}$. Modifications were made using Delftship software, Computational Fluid Dynamic, called TDyn and verified by towing tank test at Indonesian Hydrodynamics Laboratory (IHL) Surabaya. Every change of the angle of entrance bow in 3 degrees, the ship's resistance will change more and less $3.5 \%$. The smaller angle of entrance bow of the vessel the smaller ship's resistance.
\end{abstract}

\section{Introduction}

The geographical condition of Indonesia which mostly consists of sea, causing the necessity of strengthening maritime facilities and infrastructures to carry out activities of distribution of goods and sea transportation facilities, especially ships as a marine vehicle to maintain inter-island connectivity.

One of the developments of national connectivity regarding maritime is the development of pioneer ships [1]. To support the acceleration of domestic economic growth and improve inter-island connectivity in remote, deepest and outside areas, and to ensure the availability of primary commodities and the growth of trade and industry centers, the government implements the construction of pioneer vessels. One of them is the procurement of 5 units of ship type 750 DWT. The 750 DWT pioneer ship has a length of 58.5 meters, a width of 12 meters, a speed of 12 knots, and a passenger capacity of 265 people [2].

This type of pioneer ships still lacks the EEDI (Energy Efficiency Design Index) aspect as required by IMO [3], so it is necessary to modify the hull part of the vessel to reduce the resistance and energy of prime movers of the ship, which impact technically and

1 Corresponding author: ekosasmito@fft.undip.ac.id 
economically operational vessel. Optimization or modification of the hull form is one way to make ship's resistance lower [4], which will affect the use of more energy efficient.

Some concepts about the method of reduction of ship resistance by changing the entire hull form of the ship are by using the optimization method. The use of an integrated optimization module with CFD software is helpful in optimizing the overall shape of the hull with the primary function of minimizing the value of ship resistance [5]. The ship hull optimization method with the focus on the bow and stern parts or a combination of bow and stern has tried on the KSUEZMAX ship. The parametric function of modification for hull forms with the variation of SAC shape and section shape, while for stern hull also involves the variety of SAC shape and section shape [6].

The method of optimizing the ship's hull shape on a bulk carrier vessel 66,000 DWT with parametric modification function of SAC and section shape of DLWL, capable of reducing wave resistance and added resistance, both on the calm and wave sea [7].

In this research, the modified hull is carried out by varying the angle of entrance bow of the vessel \pm 12 degrees in a step of 3 degrees. Modifications were made using Delftship software, Computational Fluid Dynamic software, called TDyn and verified by towing tank test at Indonesian Hydrodynamics Laboratory (IHL) Surabaya.

\section{Methodology}

This study aims to examine the effect of changes in bow entrance angle of the Pioneer 750 DWT vessel to the overall value of the ship resistance component and to determine the entrance angle corresponding to the hull shape of the 750 DWT Pioneer vessel with the least resistance value. The calculation of ship resistance is carried out by CFD method with Tdyn software. For the initial model, CFD calculations verified by the experimental test for ship resistance in towing tanks at the Indonesian Hydrodynamics Laboratory (IHL) Surabaya. The comparison between ship and ship model is 1: 18. The ship's dimensions and ship models are shown in Table 1. The initial model line plan along with the ship's bow entrance angle shown in Figure 1. The model and 3D model of the vessel shown in Figure 2.

The bow entrance angle of the ship's initial model is 22.72 degrees. This angle is then varied every 3 degrees up to \pm 12 degrees so that the ship model changes up to 9 models including the initial model. The speed of the tested vessel is at $12-17$ knots or in the range Fr $0.26-0.36$. The resistance calculation uses Tdyn software which simulates the ship at certain speed travels in calm water and predicts its resistance. The calculation of ship resistance using Tdyn has been carried out by Samuel et al. [8] and Iqbal et al. [9]. Their CFD results are relatively good with the empirical equation proposed by Jamaluddin [10].

Table 1. Main dimension of ship and ship model of pioneer 750 DWT vessel.

\begin{tabular}{|c|c|c|}
\hline Dimension & Full Scale & Model Scale \\
\hline Length of Water Line (LWL) & $58.96 \mathrm{~m}$ & $3.276 \mathrm{~m}$ \\
\hline Breadth (B) & $11.60 \mathrm{~m}$ & $0.645 \mathrm{~m}$ \\
\hline Depth (H) & $4.50 \mathrm{~m}$ & $0.250 \mathrm{~m}$ \\
\hline Draft (T) & $2.90 \mathrm{~m}$ & $0.161 \mathrm{~m}$ \\
\hline Volume Displacement & $1107.30 \mathrm{~m}^{3}$ & $61.527 \mathrm{~m}^{3}$ \\
\hline
\end{tabular}




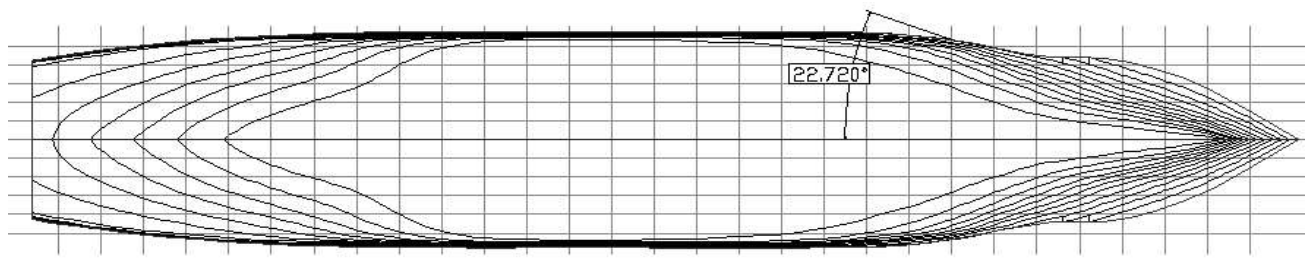

Fig. 1. Lines plan and bow entrance angle.

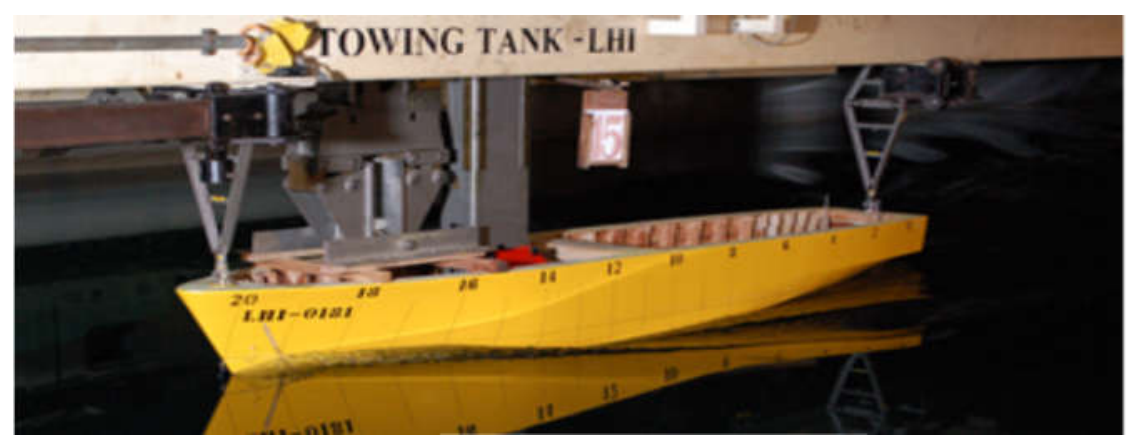

Fig. 2. Testing of ship models in LHI towing tanks.

\section{Results and discussion}

The results of CFD calculations on the initial model validated with the experimental test results in towing tank. Figure 3 shows that CFD calculations have relatively accurate results with an error less than $1 \%$ compared to the preliminary results. Furthermore, the CFD set up and meshing size in each boundary will be used for the varied models. Mesh sizes in each boundary are ship boundary 0.009 , free surface boundary 0.05 , and other boundaries 0.1 .

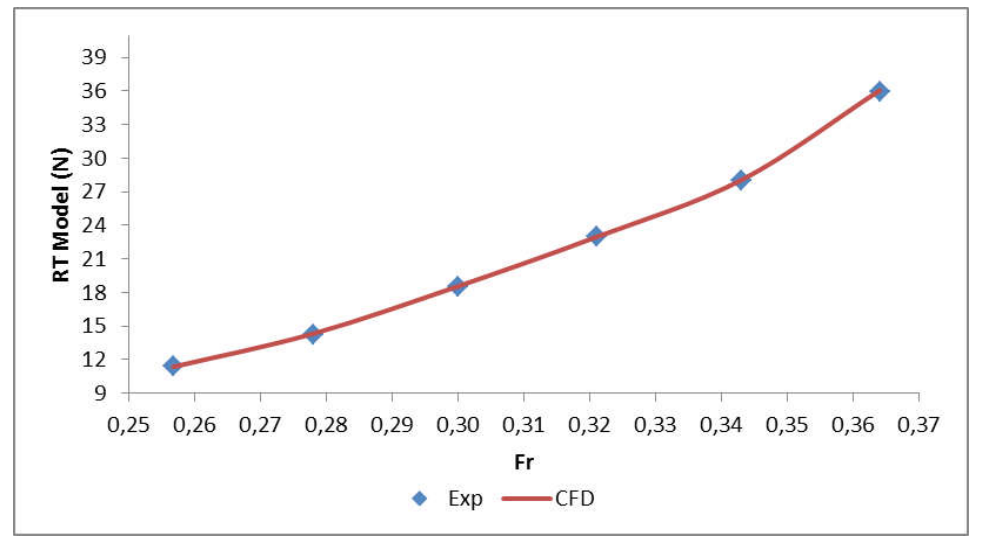

Fig. 3. The Comparison is of CFD and experimental test of ship model resistance.

Comparison of ship resistance of all models shown in Fig. 4. The bow entrance angle of the initial model, which has an angle of 22.72 degrees was varied every 3 degrees up to \pm 
12 degrees. The results show that the smaller of bow entrance angle, the more modest ship's resistance. Every change of the angle of entrance bow in 3 degrees, the ship's resistance will change more and less $3.5 \%$. This will means that the magnitude or the bow entrance angle of the vessel has a linear effect on the importance of the resistance. However, the minimum of bow entrance angle should be assessed for this ship because it will affect the size of the tank and compartment inside the vessel.

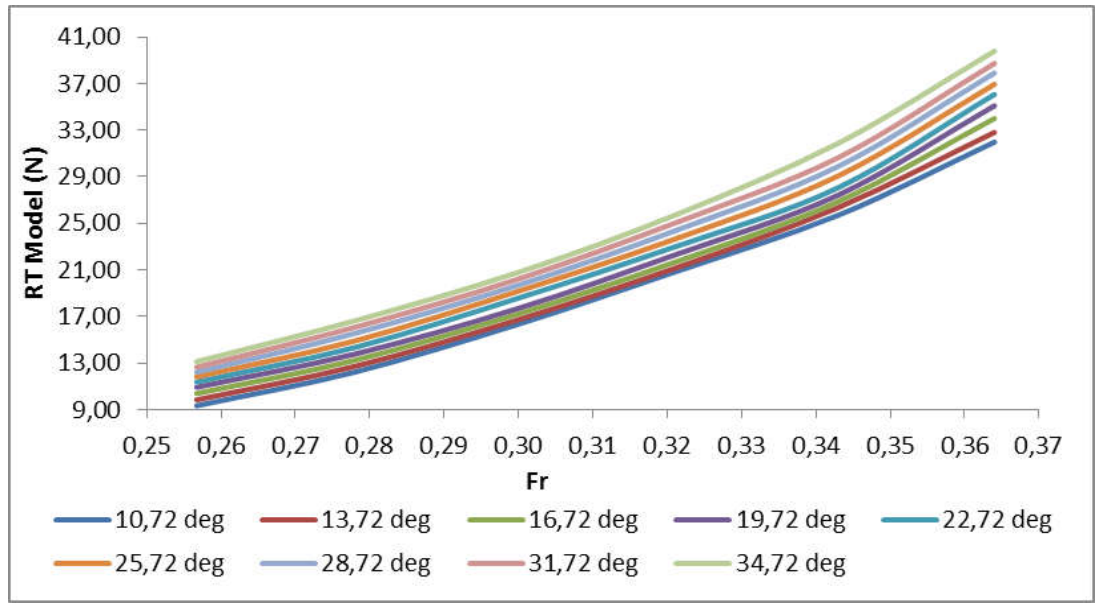

Fig. 4. The comparison is of ship model's resistance.

Table 2. The component is of ship model's resistance.

\begin{tabular}{|c|c|c|c|}
\hline Component of Ship Resistance & $\mathbf{1 0 . 7 2} \mathbf{~ d e g}$ & $\mathbf{2 2 . 7 2} \mathbf{~ d e g}$ & $\mathbf{3 4 . 7 2} \mathbf{~ d e g}$ \\
\hline Wave Resistance (RW) & $7.56 \mathrm{~N}$ & $9.70 \mathrm{~N}$ & $11.67 \mathrm{~N}$ \\
\hline Viscous Resistance (RV) & $17.81 \mathrm{~N}$ & $18.37 \mathrm{~N}$ & $18.98 \mathrm{~N}$ \\
\hline Total Resistance (RT) & $25.38 \mathrm{~N}$ & $28.07 \mathrm{~N}$ & $30.65 \mathrm{~N}$ \\
\hline
\end{tabular}

As shown in Table 2, the components of total resistance which are consist of viscous and wave resistance are presented to determine which elements are most affected by the bow entrance angle. The results of the ship resistance component introduced are the initial model and the model that was having the smallest and largest entrance angle at the service speed of 16 knots (Fr 0.343). Each component of viscous and wave resistance tends to increase as the bow entrance angle increases. Viscous resistance tends to increase by a slight margin $( \pm 3 \%)$, while the wave resistance increases by a considerable margin $( \pm 21 \%)$. This comparison proves that changes in the bow entrance angle of the vessel are more influential to the wave resistance. 


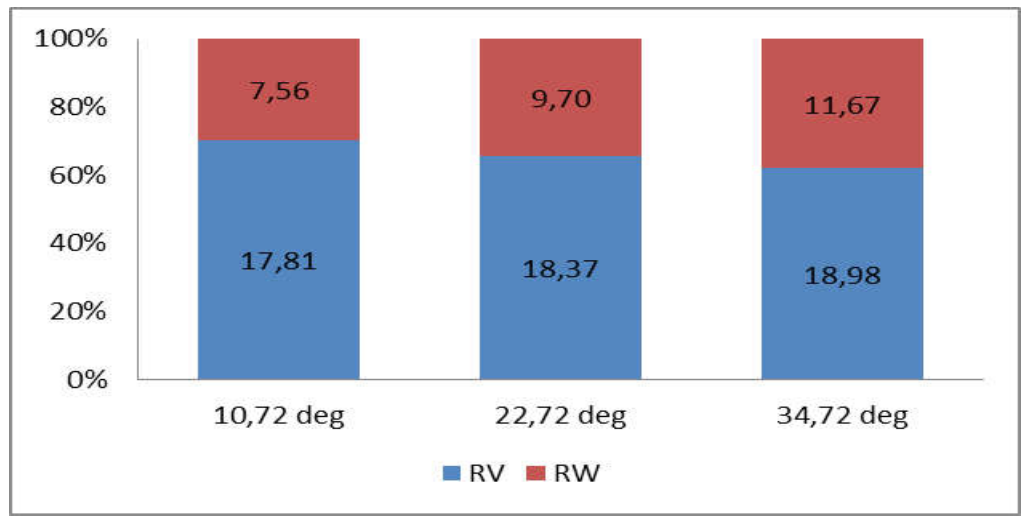

Fig. 5. Comparison of viscous and wave resistance at service speed (Fr 0.343)

Figure 5 presents the magnitude of the viscous and wave resistance ratios for each total resistance at Fr 0.343. For each model, viscous resistance is more dominant than the wave resistance. For this reason, because the ship is displacement and slow ship type. However, at the same speed, the proportion of wave resistance to its total resistance varies for different entrance angle. For the model with the smallest entrance angle, which is 10.72 degrees, the portion of wave resistance is $29.8 \%$ of the total ship resistance, followed by $34.57 \%$ for the initial model with the angle of 22.72 degrees and $38.06 \%$ for the most significant angle model, 34.72 degrees. As the wave resistance is low at small bow entrance angle, Figure 6 shows that at the same speed (Fr 0.343) the lowest bow entrance angle has the low wave elevation.

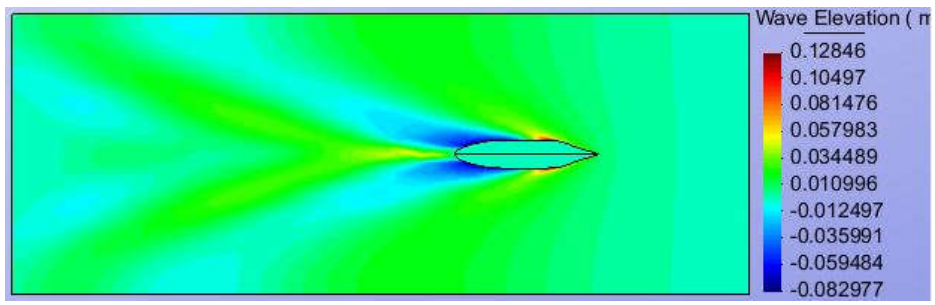

(a)

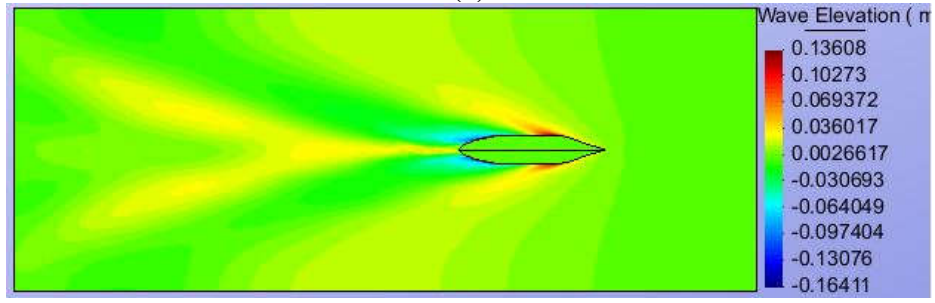

(b)

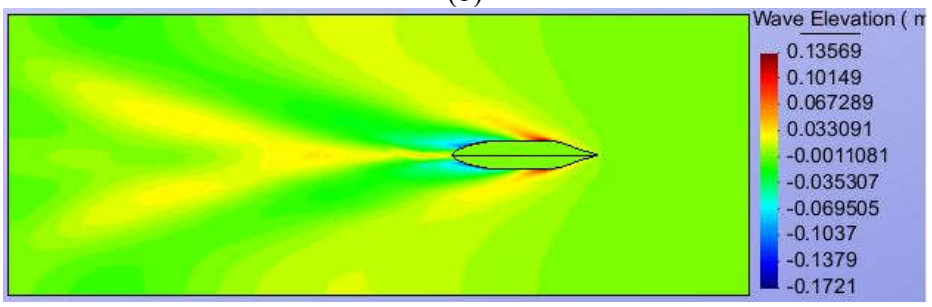

(c) 
Fig. 6. Comparison of wave elevation at service speed (Fr 0.343). (a) Bow entrance angle $10.72^{\circ}$ (b) bow entrance angle $22.72^{\circ}$ (c) bow entrance angle $34.72^{\circ}$

\section{Conclusion}

At the service speed (Fr 0.343), the resistance of initial ship model with an entrance angle 22.72 degrees is $28,067 \mathrm{~N}$. While ship model with the smallest angle, 10.72 degrees, the ship's resistance is $25.7 \mathrm{~N}$ or decreased up to $8.43 \%$. For ship model with the most significant edge, which is 34.72 degrees, the ship's resistance is increased up to $13.57 \%$ or $31.878 \mathrm{~N}$. Every change of the angle of entrance bow in 3 degrees, the ship's resistance will change more and less $3.5 \%$. Reduced angle of entry will have an impact on the reduction of ship resistance.

\section{References}

1. L. Adam, Politica, Kebijakan Konektivitas Maritim Di Indonesia (Maritime Connectivity Policy in Indonesia, 6 (1), 20-41, (2015)

2. Directorate General of Sea Transportations. "Dukung Program Tol Laut, 50 Kapal Perintis Dan 3 Kapal Perambuan Mulai Dibangun." http://www.dephub.go.id/berita/baca/dukung-program-tol-laut,-50-kapal-perintis-dan3-kapal-perambuan-mulai-dibangun/?cat=QmVyaXRhfHNlY3Rpb24tNjU $=(2015)$

3. Z. Bazari, M2 Ship Energy Efficiency Regulations and Related Guidelines IMO Train the Trainer (TTT) Course on Energy Efficient Ship Operation Module 2 - Ship Energy Efficiency Regulations and Related Guidelines MODULE 2 Ship Energy Efficiency Regulations and Related Guidelines Module Aims and Objectives, http://www.imo.org/en/OurWork/Environment/PollutionPrevention/AirPollution/Docu ments/Air pollution/M2 EE regulations and guidelines final.pdf (2016)

4. ABS. "Ship Energy Efficiency Measures; Status and Guidance." American Bureau of Shipping. $\quad \mathrm{http}$ ://www.eagle.org/eagleExternalPortalWEB/ShowProperty/BEA Repository/References/Capability Brochures/ShipEnergyEfficiency. (2013)

5. F. Huang, C. Yang, Hull form optimization of a cargo ship for reduced drag, Journal of Hydrodynamics, 28 (2), 173-183, (2016)

6. J-H. Park, J-E. Choi, H-H. Chun, Hull-form optimization of KSUEZMAX to enhance resistance performance, International Journal of Naval Architecture and Ocean Engineering, 7 (1), 100-114, (2015)

7. J-W. Yu, C-M. Lee, I. Lee, J-E. Choi, Bow hull-form optimization in waves of a 66,000 DWT bulk carrier, International Journal of Naval Architecture and Ocean Engineering, 9 (7), 499-508, (2017)

8. Samuel, M. Iqbal, I.K.A.P. Utama, An investigation into the resistance components of converting a traditional monohull fishing vessel into catamaran form, Int. J. of Tech, 6 (3), 432-441, (2015)

9. M. Iqbal, Samuel, Traditional catamaran hull form configurations that reduce total resistance, Int. J. of Tech, 8 (1), 85-93, (2017)

10. A. Jamaluddin, I.K.A.P. Utama, B. Widodo, A. Molland. Experimental and numerical study of the resistance component interactions of catamarans. J. of Eng. for the Maritime Environment, 227, 51-60, (2012) 